\title{
Porcine Leukemia
}

National Cancer Institute

\section{Source}

National Cancer Institute. Porcine Leukemia. NCI Thesaurus. Code C141365.

Leukemia that occurs in a pig. 